\title{
A true epidermotropic apocrine neoplasm in the form of perianal Paget's disease: a case report
}

\author{
Nikola Jankulovski ${ }^{1}$, Liljana Spasevska ${ }^{2}$, Vesna Janevska ${ }^{2}$ and Blagica Dukova ${ }^{2 *}$
}

\begin{abstract}
Introduction: Extramammary Paget's disease is an uncommon intraepithelial neoplasm that arises in areas rich in apocrine glands. Treatment includes wide surgical excision and nonsurgical modalities. We present the case of a patient with perianal Paget's disease with no recurrent disease after wide surgical resection.

Case presentation: Our patient was a 46-year-old man of Macedonian ethnicity who presented with a pruritic perianal lesion measuring up to $6 \mathrm{~cm}$ without pain or bleeding. Two biopsies and a perianal wide surgical excision were performed. The tissue specimens were formalin-fixed and the paraffin-embedded samples analyzed according to standard histochemical and immunohistochemical procedures.

Surgical perianal skin excision revealed diffuse eczematoid, whitish plaques. Pathohistology showed Paget cells infiltrating his epidermis and adnexal epithelium, with ulceration. Immunohistochemical analysis revealed positive Paget cell expression for cytokeratin 7, epithelial membrane antigen, carcinoembryonic antigen, androgen receptor and human epidermal growth factor receptor 2, and negative expression for cytokeratin 20 and melan-A.
\end{abstract}

Conclusion: Paget's disease is a rare disorder that should be considered in the differential diagnosis of perianal lesions. Reporting cases of extramammary Paget's disease is crucial for diagnostic guidelines and different therapeutic options.

\section{Introduction}

Extramammary Paget's disease (EMPD) is a rare cutaneous neoplasm that mainly affects the elderly. It predominantly involves apocrine gland-bearing areas, especially the vulva, scrotum and perianal region, but also the axilla, groin, thigh, external ear, umbilicus and nose [1]. Perianal Paget's disease (PPD) was first described by Darier and Couillaud in 1893 [2]. There have been less than 200 reported cases in the literature, and the true incidence is difficult to estimate. PPD occurs either alone or in association with other adnexal malignancies or adenocarcinoma of the gastrointestinal tract. Clinical presentation includes nonspecific symptoms such as long-standing perianal eczema or pruritis, rash, bleeding, discharge and occasionally pain. Most of these lesions are first treated as benign dermatologic conditions with topical corticosteroids and antifungal therapy. The diagnosis is made by pathohistology and the treatment

\footnotetext{
* Correspondence: blagicadr@yahoo.com

${ }^{2}$ Institute of Pathology, Medical Faculty, University "St Cyril and Methodius", Skopje, Republic of Macedonia

Full list of author information is available at the end of the article
}

includes wide surgical excision and other treatment modalities. The rarity of the disease means that no large studies can be made, so it is crucial to report as many cases as possible in the literature to inform diagnostic guidelines and different therapeutic options. We present a case of PPD in a male patient with no other adnexal or gastrointestinal malignancy.

\section{Case presentation}

A 46-year-old man of Macedonian ethnicity presented with a pruritic perianal lesion measuring up to $2 \mathrm{~cm}$ without pain or bleeding. Our patient was diabetic and had a family history of diabetes and hypertension. Five months after his initial presentation, a colonoscopy and a biopsy were performed at Clinical Hospital Sistina Adzibadem. The next month, our patient was admitted to our University Clinic of Digestive Surgery, where a physical examination revealed a perianal eczematous lesion measuring $6 \times 4 \mathrm{~cm}$ and enlarged inguinal lymph nodes. A second biopsy with a left lymphadenectomy was performed.

\section{Biomed Central}


The tissue specimens were formalin-fixed and paraffinembedded at our Institute of Pathology. We used a routine hematoxylin-eosin stain and performed additional histochemical and immunohistochemical analysis, including staining with Alcian blue and for cytokeratin (CK)7, CK20, epithelial membrane antigen, carcinoembryonic antigen, melan-A, androgen receptor and human epidermal growth factor receptor 2 (Her2/neu).

Microscopic analysis of the biopsy specimens showed large Paget cells with abundant pale cytoplasm, and large nuclei infiltrating the basal part and the whole thickness of the squamous epithelium and adnexal epithelium. Occasional cells had a signet-ring appearance. His inguinal lymph node revealed reactive lymphadenopathy. A diagnosis of EMPD was made.

The perianal surgical skin excision measured $5.5 \times 6.5 \times$ $0.7 \mathrm{~cm}$ and showed diffuse ulcerated eczematous plaques (Figure 1). Histopathology revealed identical Paget cells as viewed in the biopsy specimen, infiltrating the epidermis and adnexal epithelium with ulceration. In the basal epidermal layers there were some duct-like structures with small central lumina (Figures 2 and 3). There was intense mononuclear infiltrate in the dermal connective tissue. An immunohistochemical analysis on both biopsy and excision specimens revealed positive Paget cell expression for CK7, epithelial membrane antigen, carcinoembryonic antigen, androgen receptor and Her2/neu (Figures 4, 5 and 6), and negative expression for CK20 and melan-A. Intracytoplasmic sialomucin stained positive for Alcian blue (Figure 7). A diagnosis of primary in situ PPD was made.

After two biopsy findings of EMPD, a wide surgical excision was performed (Figures 8 and 9). The patient was discharged in good condition and advised to attend a follow-up examination. After six months, a check-up revealed his skin area to be disease free.

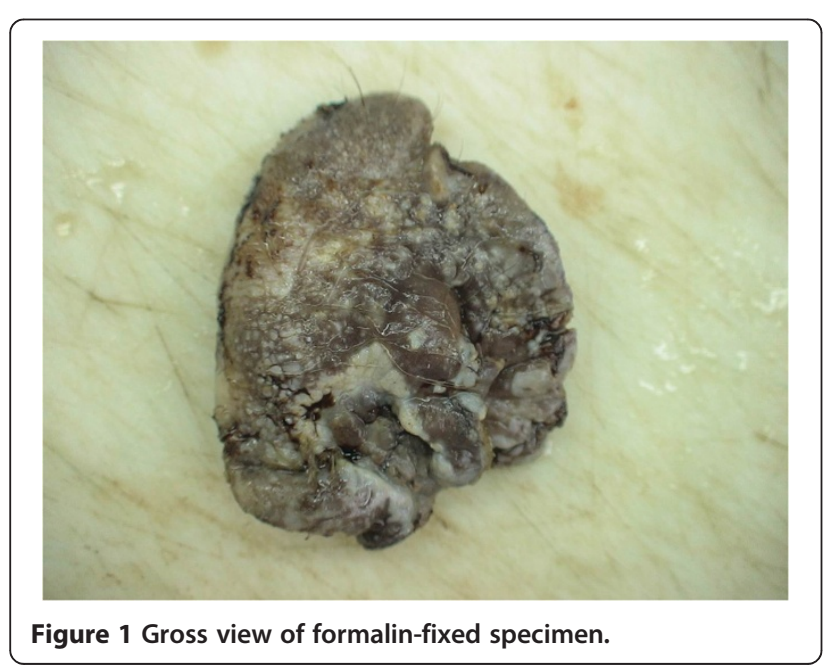

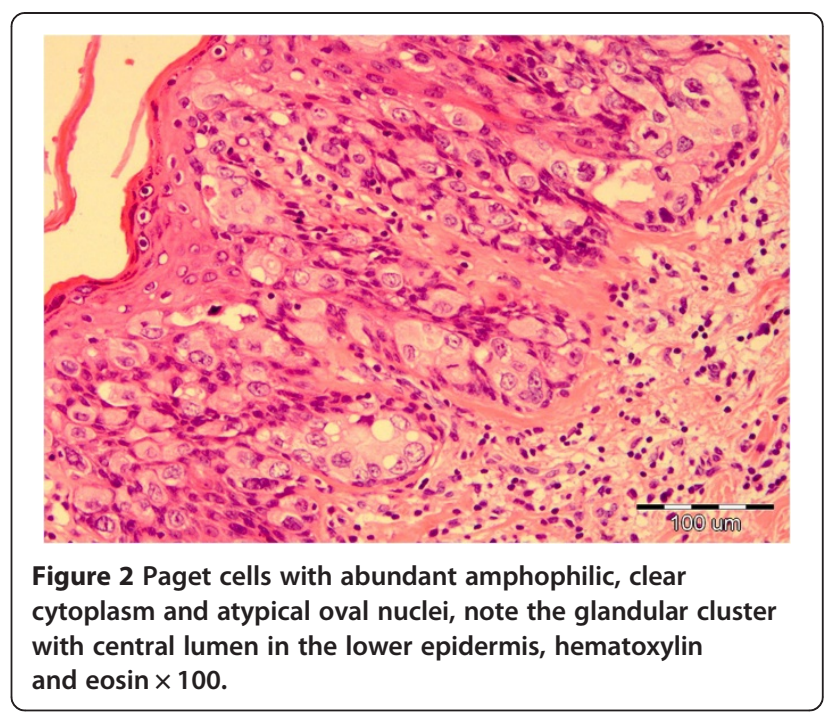

\section{Discussion}

EMPD is a rare cutaneous intraepithelial adenocarcinoma arising in apocrine gland-bearing areas, particularly the perineum, vulva, axilla, scrotum, penis and groin. PPD mostly refers to intraepithelial carcinoma within $6 \mathrm{~cm}$ of the anus and below the dentate line [3]. Patterns of involvement include an in situ epithelial form without associated carcinoma, an epithelial form with associated adnexal carcinoma, and association with visceral malignancy. Paget cells have the potential to invade the dermis and to metastasize. The anatomic site of the presenting EMPD is strongly related to the underlying visceral carcinoma in $86 \%$ of cases [4]. Our patient had an intraepithelial lesion without invasion of the dermis and no associated colorectal carcinoma.

Clinical presentation is often nonspecific and the diagnosis is frequently overlooked. Patients commonly have symptoms like pruritus, irritation and rash, although pain and bleeding may occur in long-standing cases.

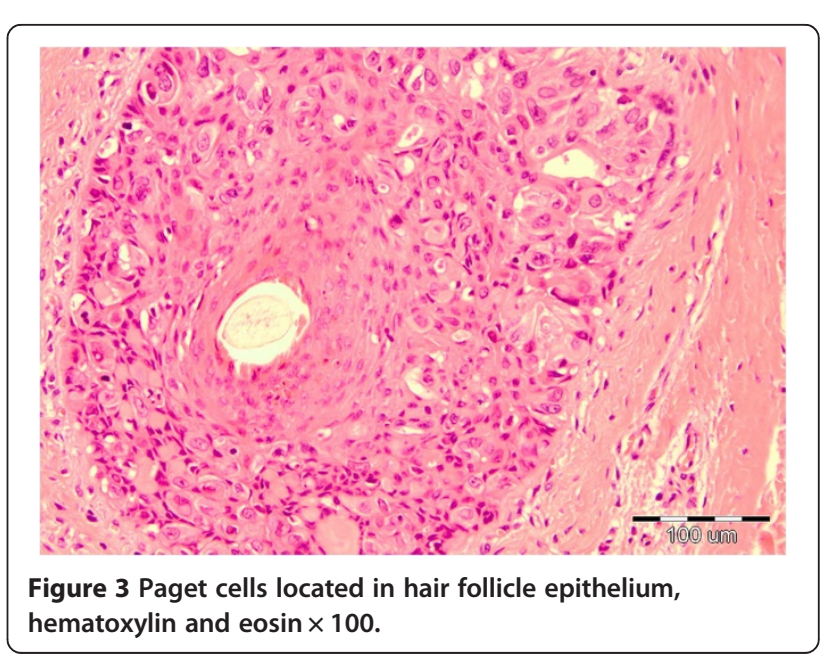




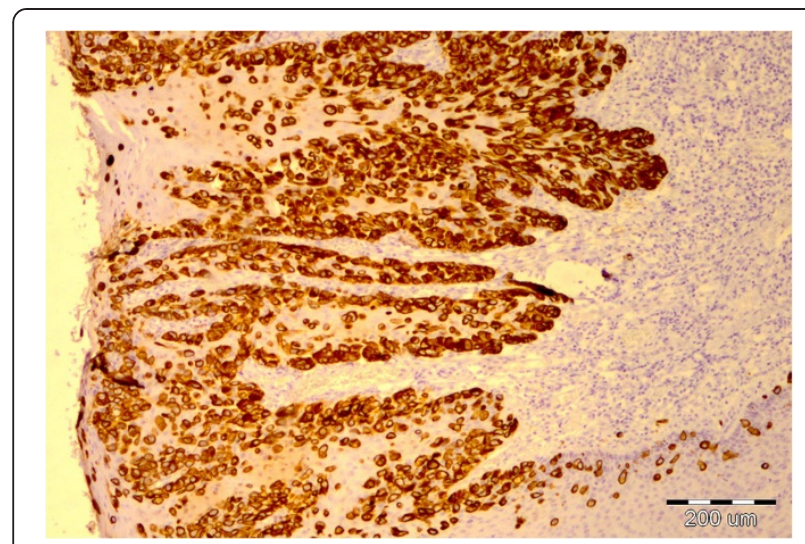

Figure 4 Intraepithelial Paget cells showing strong membrane staining for cytokeratin $7, \times 40$.

These lesions are typically erythematous, or whitish gray, dry and raised, but may turn into eczematoid, ulcerated, nodular or papillary forms [5-10]. It is unusual to make a diagnosis of EMPD clinically, so this condition is often first treated with topical corticosteroids and antifungal agents before a diagnosis is made by biopsy.

Differential diagnoses include Bowen's disease, contact dermatitis, lichenoid lesions, psoriasis, melanoma, perianal Crohn's involvement, mycosis fungoides, squamous cell carcinoma and tinea cruris.

Histopathology reveals large, round, clear-staining cells with abundant pale cytoplasm confined to the epidermis. The nuclei are large and situated in the periphery of cells. In the lower epidermal layers, glandular clusters can be seen that are absent in mammary Paget's disease. Liu et al. [11] support the theory of two types of PPD with different immunoprofiles: primary cutaneous intraepithelial neoplasm (CK7-positive and CK20negative), in which cells display sweat gland differentiation (gross cystic disease fluid protein 15-positive); and

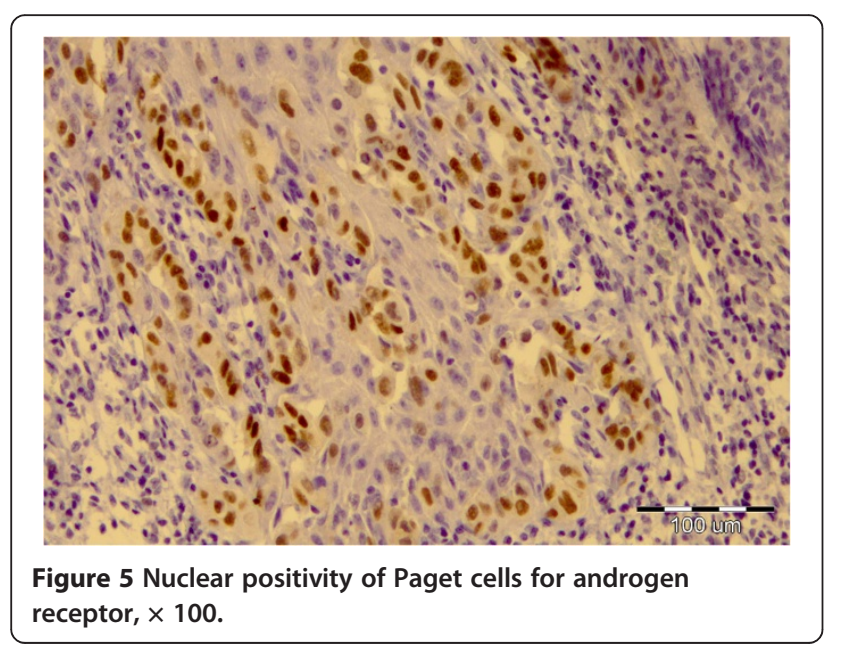

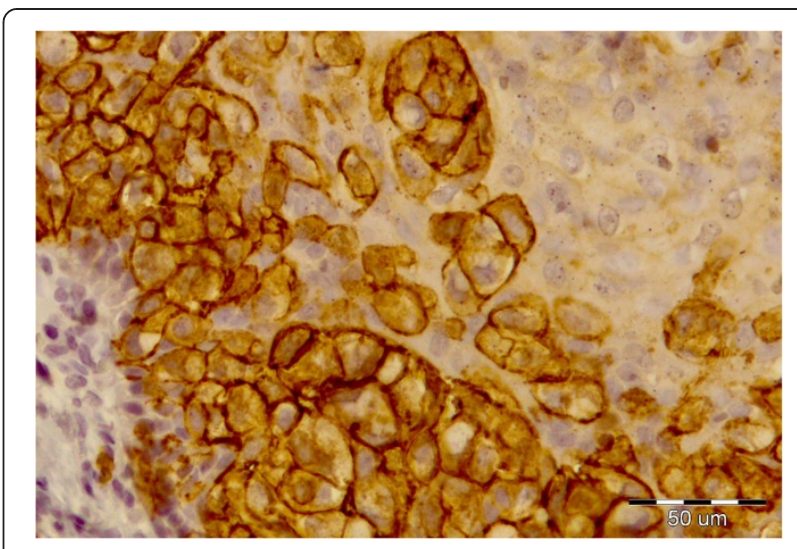

Figure 6 Complete membrane staining (3+) of Paget cells for human epidermal growth factor receptor $2, \times 200$.

direct intraepithelial Pagetoid spread of anorectal adenocarcinoma (CK20-positive and CK7-negative, gross cystic disease fluid protein 15-negative). In one study, cells were androgen receptor-positive in $78 \%$ of patients and Her2/neu-positive in 52\%. Coexpression, as in our patient, existed in $52 \%$ of patients [12].

Pathogenesis of PPD is controversial. Helwig and Graham [4] consider perianal and vulvar Paget's disease to be a manifestation of a multicentric effect of an unknown carcinogenic stimulus on apocrine structures, epidermis and glandular elements of the rectum and urethra.

A patient diagnosed with EMPD needs an initial clinical assessment, evaluation of the extent of involvement of the lesion, and work-up for a possible underlying malignancy. A wide range of treatment modalities have been reported, including surgical and nonsurgical approaches. Surgical methods are still the mainstay in the management of PPD, including wide local excision with or without reconstruction and grafting, abdominoperineal

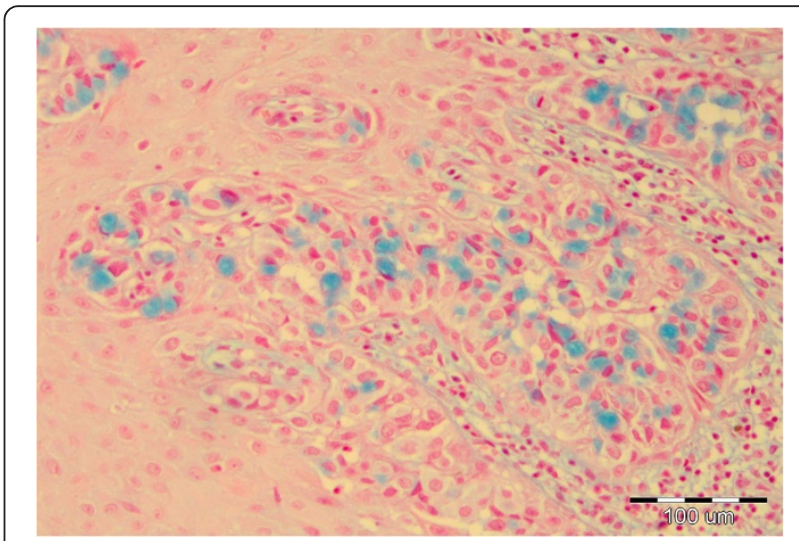

Figure 7 Intracytoplasmic mucine in Paget cells, Alcian blue $\times 100$. 


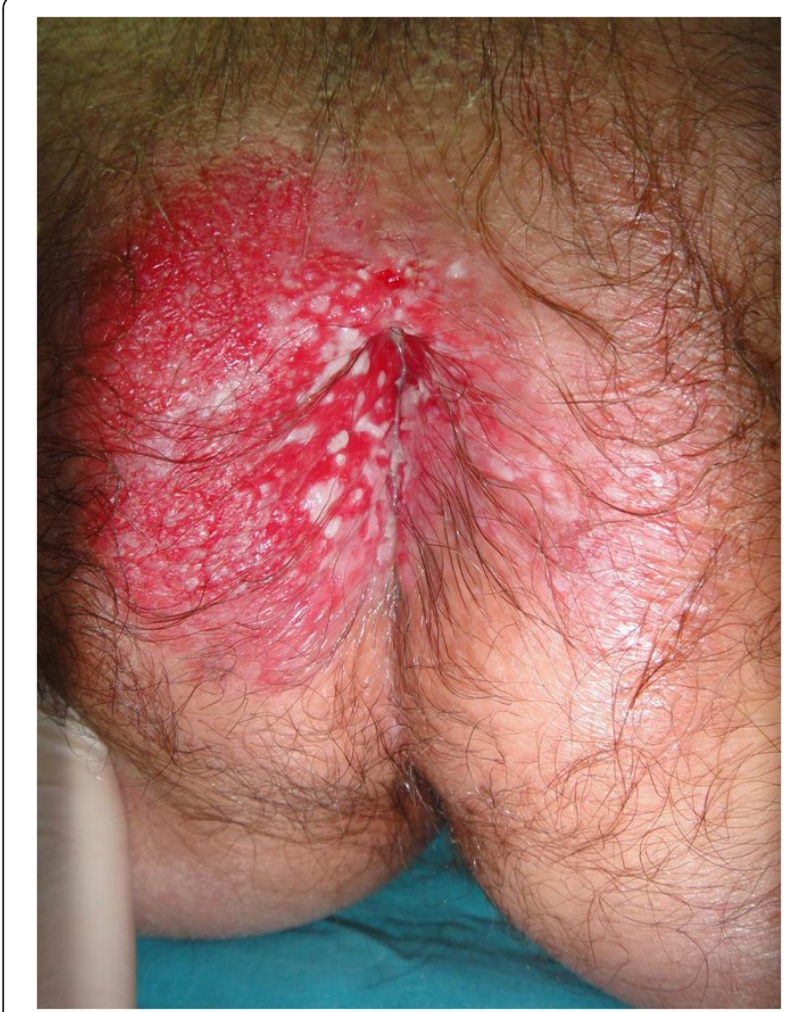

Figure 8 Clinical features of a patient with perianal Paget's disease.

resection, and Mohs micrographic surgery. Radiotherapy, chemo-radiotherapy and photodynamic therapy have been employed $[6,7,13]$. Despite varied modalities, local recurrence is a significant problem, to the extent of 33\% [5]. The major factors in relapse and chronicity of the disease are multifocal involvement and difficulty in clinical delineation of cutaneous margins.

Prognosis depends on whether the disease extends beyond the epidermis and the adnexal epithelium. If it is

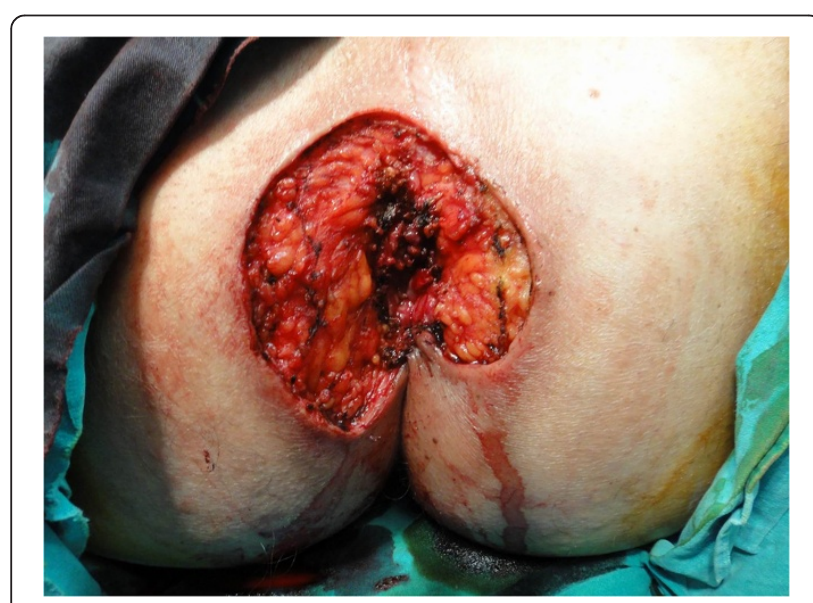

Figure 9 Post surgical excision. associated with subjacent adnexal carcinoma or regional visceral carcinoma, the prognosis is poor. Survival of patients with in situ PPD is favorable.

Long-term follow-up of patients with EMPD is required to exclude the recurrence of the disease and development of an associated cancer. Follow-up should include a punch biopsy from the margin of the old perianal lesion once a year, in addition to a colonoscopy once every two years [1].

\section{Conclusion}

We present the case of a patient with PPD treated with wide surgical excision. Our patient has demonstrated a disease-free period of six months. The diagnosis was made using pathohistology and immunohistochemistry. Although surgical excision is the proposed treatment of choice, other therapy modalities are used but not yet standardized. Long-term follow-up is essential to detect local recurrence and development of invasive Paget's disease or anorectal carcinoma.

\section{Consent}

Written informed consent was obtained from the patient for publication of this case report and accompanying images. A copy of the written consent is available for review by the Editor-in-Chief of this journal.

\section{Abbreviations \\ CK: cytokeratin; EMPD: extramammary Paget's disease; PPD: perianal Paget's disease.}

\section{Competing interests}

The authors declare that they have no competing interests.

\section{Authors' contributions}

$\mathrm{NJ}$ performed the biopsies and wide surgical excision, analyzed the data and followed-up the patient. LS, VJ and BD performed the histological examination of the specimens and interpreted the patient data. NJ and BD were major contributors in writing the manuscript. All authors have read and approved the final manuscript.

\section{Author details}

"University Clinic of Digestive Surgery, University "St Cyril and Methodius", Skopje, Republic of Macedonia. ${ }^{2}$ Institute of Pathology, Medical Faculty, University "St Cyril and Methodius", Skopje, Republic of Macedonia.

Received: 8 February 2013 Accepted: 7 May 2013

Published: 20 June 2013

\section{References}

1. Rao VR, Henry DH: Extramammary Paget's disease. Commun Oncol 2004, 1:109-114.

2. Darier J, Couillaud P: Sur un case de maladie de Paget de la region perinea-annale et scrotale. Soc Fr Dermatol Syphilogr 1893, 4:25-31.

3. Lian P: Retrospective analysis of perianal Paget's disease with underlying anorectal carcinoma. World J Gastroenterol 2010, 16:2943-2948.

4. Helwig EB, Graham JH: Anogenital (extramammary) Paget's disease. A clinicopathological study. Cancer 1963, 16:387-403.

5. Chen SB, Lee WJ: Paget's disease of anus: a case report. J Soc Colon Rectal Surgeon (Taiwan) 2009, 20:69-73.

6. Banerjee S, Chatterjee M, Chand K: Extramammary Paget's disease. Indian J Dermatol Venereol Leprol 2005, 71:417-420.

7. Al-Alawi AH: Perianal Paget's disease. Bahrain Medical Bulletin 2006, 28:47-49. 
8. Amin R: Perianal Paget's disease. Br J Radiol 1999, 72:610-612.

9. Ekwueme KC, Zakhour HD, Parr NJ: Extramammary Paget's disease of the penis: a case report and review of the literature. $J$ Med Case Reports 2009, 3:4.

10. Wang $X$, Yang W, Yang J: Extramammary Paget's disease with the appearance of a nodule: a case report. BMC Cancer 2010, 10:405.

11. Liu C, Wang Q, Kong Y, Tu X, Wang J, Zhu X: A clinicopathological study of perianal Paget's disease associated with internal rectal adenocarcinoma. Zhonghua Bing Li Xue Za Zhi 2004, 33:11-15.

12. Liegl B, Horn LC, Moinfar F: Androgen receptors are frequently expressed in mammary and extramammary Paget's disease. Mod Pathol 2005, 18:1283-1288.

13. Nardelli AA, Stafinski T, Menon D: Effectiveness of photodynamic therapy for mammary and extra-mammary Paget's disease: a state of the science review. BMC Dermatol 2011, 11:13.

doi:10.1186/1752-1947-7-162

Cite this article as: Jankulovski et al:: A true epidermotropic apocrine neoplasm in the form of perianal Paget's disease: a case report. Journal of Medical Case Reports 2013 7:162.

\section{Submit your next manuscript to BioMed Central and take full advantage of:}

- Convenient online submission

- Thorough peer review

- No space constraints or color figure charges

- Immediate publication on acceptance

- Inclusion in PubMed, CAS, Scopus and Google Scholar

- Research which is freely available for redistribution 